be done for the external variety of anthrax. The wet cure of hides is largely adopted by the trade instead of the dry cure. It should be universal. For the internal varieties of the disease important regulations have been drawn up by the sanitary committee of the Bradford town council. These regulations, important as they are, are, in my opinion, not so good as those originally suggested by Dr. T. W. Hime, the medical officer of health of Bradford.

Hove.

\section{Clinical êtotes:}

\section{MEDICAL, SURGICAL, OBSTETRICAL, AND THERAPEUTICAL.}

\section{NOTE ON A CASE OF CHOREA TREATED BY THYROID EXTRACT.}

By Percy A. Roden, M.D. Aberd.,

hoNoRary PHYSICIAN TO THE BRINE baths HOSPITAL, DROITWICH.

THIS case having caused me a considerable amount of anxiety, I publish it with the hope that others who have had similar cases may relate their experiences and so shed a further light on this very distressing malady.

The patient, a girl, aged 10 years, was brought to me three years ago with acute symptoms of chorea. Her restlessness was very marked, more especially in the arms and legs which were never quiet. The face and neck were very slightly affected. There were no facial twitchings, but an occasional jerk of the head to one side. The heart appeared to me quite normal; there was no murmur to be detected at the apex or at the base; the apex beat was not displaced, and there was no indication of any enlargement. I treated the child with arsenic in steadily increasing doses, at the same time giving gentle saline aperients (sodii phosph.), and ordering a simple diet which should be nourishing and at the same time not irritating-viz., porridge made of quaker oats, plenty of milk and cream, farinaceous puddings, vegetables, and ripe fruit. The child, however, showed no improvement. I ordered her to remain away from school, and commenced a course of treatment with potassium iodide, and as that gave no result I tried the combination of iodide with the bromide of potassium, still with no improvement. After having tried salicylates and quinine without good effect $I$ took the child into St. John's Hospital for brine baths, and in a fortnight she was able to return home apparently well. She then returned to school, but in a month's time the jerky movements and want of coördination began to return, and the child became listless and showed signs of wasting. I ordered her once more to be kept from school, and prescribed codliver oil together with bromide and iodide of potassium, and then as she showed no improvement I took ber once more into St. John's Hospital where she quickly lost her jerky movements, and was able to return home apparently quite well.

I was greatly in hopes that this second course of brine treatment would prove permanent. I did not see the child for some months, but was asked by the mother at the beginning of this year to call and see her, as she was worse than ever. Accordingly $I$ went and found the girl suffering badly. Her mother begged me to take her once more into the hospital, which I intended to do, but while talking to her the other children (two girls) came in from school looking rosy and well, "and I noticed that each of them suffered with goitre. I then examined the throat of $\mathrm{my}$ patient, but found no trace of goitre. I could not help thinking that perhaps she might have some thyroid insufficiency so I gave her teaspoonful doses of the fluid extract of the thyroid gland (prepared by Duncan and Flocikhart of Edinburgh) twice a day with the most surprising result. The child showed marked improvement in the first week and returned to school in the second week, still continuing with the thyroid extract. With this she persevered twice a day for a month, and then was ordered to take it only once a day for the next month.

I have seen the child frequently and she looks rosy and well, showing no sign of chorea. This improvement has now beer maintained for over nine months.

Droitwich.

\section{A CASE OF CONCURRENT EXTRA- AND INTRA- UTERINE PREGNANCY.}

By Francis W. Davidson, M.B., Ch.B. Aberd., TATE MOUSE SURGEON, ROYAL HOSPITAL, RICHMOND.

ON the morning of Feb. 9th of this year I was called in to see a woman, aged 32 years, who had been seized with a sudden sharp pain in the right side of her abdomen. I found the patient in bed in a collapsed condition. She was very pale and her pulse was small, rapid, and thready. Her symptoms and general appearance were those of internal hæmorrhage. The history was briefly as follows. She had not menstruated since the middle of December, 1909. At intervals during these two months of amenorrhoea she had sharp pains in her right side, but as they did not last long she had not sought medical advice.

On examination I found she was very tender over the lower part of her abdomen and quite dull in the flanks. I diagnosed ruptured ectopic gestation and ordered her immediate removal into the Oroydon General Hospital. She was admitted under Dr. J. Wayte, who performed a right-sided coliotomy the same afternoon. On examining the ex. tracted ovum he found two foetus of about two months' development. The patient made a good recovery and was discharged from the hospital on March 13th. About the middle of May she informed me that she thought she was still pregnant, as she had "felt the baby moving" since the end of April. I told her to come back and see me in a couple of months. This she did, and an examination left me in no doubt that she was about seven months pregnant. I gave her the middle of September as the probable date of accouchement and on Sept. 17th I delivered her of a healthy full-term female child. There was no trouble with the abdominal scar at the confinement and the patient had a perfectly uneventful puerperium.

Thornton Heath.

\section{VASO-MOTOR RHINITIS OF 20 YEARS' DURATION; SUBMUCOUS RESECTION; COMPLETE RECOVERY.}

By Charles A. Adair Dighton, F.R.C.S. Edin., HONORARY OPHTHALMIC AND AURAL SURGEON TO THE SCARBOROYGH HOSPITAL.

THE following case, which came under my charge early in April of this year, seems worthy of notice.

A well-built, particularly healthy-looking man, aged 30 years, came to me complaining of attacks of hay fever and rhinorrhcea occurring regularly every seventh day and completely incapacitating him from work on those days. He had been a butler, but owing to the disease had to give up his situation and is now a painter. Twenty years ago he had an attack of influenza and bronchial asthma, since which time he had had an attack of hay fever and rhinorrbœe every seventh day, He had been to several infirmaries and had had his frontal sinus opened and both sides of the nose cauterised with no effect. There was no history of accident or injury. On examination the nasal septum was found to be markedly deflecteo to the right side, showing a large bend in the superior portion and a large ridge on the vomer in the lower portion. The concavity on the left side was compensated for by a large middle turbinal. No polypi or pus was present, and the antrum was normal on transillumination. Under cocaine adrenalin anæesthesia I removed the nasal septum and ridge by the submucous method. The man returned to work on the third day after the operation and has continued at it ever since, with no sign whatever of any recurrence of the symptoms and has had no treatment whatever beyond a menthol spray after the operation followed by an alkaline douche, these being altogether stopped at the end of a fortnight.

The chief points of interest seem to be: (1) the ante. cedent bronchial asthma and influenza, probably setting up a condition of hypertrophic turgescent rhinitis in an already predisposed nasal cavity, the turgescence increasing for seven days and terminating in an attack of rhinorrhoea and hay fever ; (2) the extraordinary periodicity of the attacks ; and (3) the severity of them. Ballenger in his book notes a case of coryza cedematosa which appears somewhat similar, but in it the patient showed several œdematous spots, which 
were entirely absent in my case, as the only signs present were a seemingly acute hypertrophy and turgescence of the mucous membrane during the attack, whilst between attacks the nose, except for deformity and enlarged turbinals, was normal in appearance.

Scarborough.

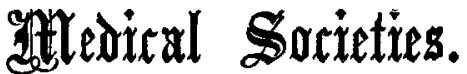

\section{MEDICAL SOCIETY OF LONDON.}

\section{The Clinical Aspects of Melastatic Cancer of the Ovary.} A MEETING of this society was held on Oct. 24th, Mr. CharTers J. Symonds, the President, being in the chair.

Mr. J. BLAND-SutToN read a paper on the Clinical Aspects of Secondary (Metastatic) Cancer of the Ovary. He said that the subject of cancer of the ovary had interested him during a quarter of a century; during the whole of that period he entertained the gravest doubt in regard to the existence of primary cancer of the ovary. He was still in doubt concerning it. Observations published during the last eight years had established the fact that solid tumours of the ovary large enough to be perceptible to eye and hand in the hypogastrium, which on microscopic examination exhibited the structure of carcinoma, were nearly always secondary to primary foci of cancer in the breast, gall-bladder, or some part of the gastro-intestinal tract, especially the pylorus and colon. Many large solid tumours of the ovary, unilateral and bilateral, which exhibited the structure peculiar to cancer, and regarded as arising primarily in the ovary, were, in truth, secondary to cancer in some other organ. When patients were submitted to operation for solid ovarian tumours, especially if the tumours were bilateral and ascompanied by vomiting and ascites, a carefal examination should be made of the abdominal viscera, especially the stomach and sigmoid flexure of the colon. Some pathologists who willingly admitted that the solid cancerous tumours, such as had just been considered, were metastatic, still believed that many cystic ovarian tumours with a cancerous structure were primary. When cancer attacked the stomach, cæcum, or gall-bladder, the cancerous cells permeated the muscular and serous coats in relation with the primary growth and found their way into the general peritoneal cavity. Many of those cells were conveyed by the peritoneal fluid into the recesses of the pelvis and lodged on the ovaries, Fallopian tubes, and uterus. Cells which fell upon the ovaries implanted themselves, grew, replaced the ovarian tissue, and in some instances became large and easily recognisable tumours. From his observations he had come to the conclusion that when the cancerous cells implanted themselves upon a normal ovary the result wonld be a solid tumour, but it occasionally happened that cancer arose in the gastro-intestinal tract of a woman who had a cystic ovary. In such circumstances the cancerous particles implanted themselves on the wall of the cyst and grew quickly into large and formidable masses. In addition he had to add the Fallopian tube. Primary cancer of the Fallopian tube was a very malignant form of cancer, and the operative treatment of this disease had rarely been followed by enduring success. It was a well-known fact that when the mucous membrane of a Fallopian tube was infected with pathogenic micro-organisms, the changes in the tubal tissues resulting from such infection led to the complete occlusion of the ccelomic ostium of the tube. Some years ago he was able to demonstrate that an occluded ostium occasionally occurred in cancerous Fallopian tubes and that the closure of the mouth of the tube exercised an important influence on the course of the disease. When the ostium of the tube remained open the cancerous particles were poured out cornucopial fashion into the pelvis, and soiled all the adjacent tissues and organs. Nearly all the patients who submitted to operation for the removal of a cancerous tube, in whom the mouth of the tube remained open died with re currence of the disease within a year. It must not be imagined that the implantation of cancer on the walls of ovarian cysts was an uncommon event. Within a period of 18 months (from March, 1909, to October, 1910) seven examples had come under his observation. The primary foci were distributed among the following organs: stomach, 2; hepatic flexure of colon, 1 ; sigmoid flexure of colon, 1 ; uterus, 1 ;
Fallopian tube, 1 ; and in 1 the primary focus was undetermined. The question naturally arose as to the advisability of operating in many cases of that kind. The same argument applied to operations performed for the relief of cancer in any situation. When patients came under observation with a tumour of the size of a football in the lower half of the abdomen which was interfering with the bladder, the rectum, or both those organs, producing pain and great distress, perhaps accompanied by vomiting, the surgeon was bound to give the patient relief. No surgeon hesitated to perform colotomy in patients with acute intestinal obstruction caused by cancer in the upper part of the rectum. The surgeon would rarely have any difficulty in satisfying his conscience concerning the necessity of an operation, but he would at times be sorely tried when determining how much or how little he should remove. On several occasions he had removed bilateral ovarian cancerous masses and the uterus, and in the same operation removed a cancerous obstruction in the sigmoid flexure and joined the ends by circular enterorrhaphy. In some instances the patients had survived the operation and lived in comfort two or more years. It was more common for death to ensue within a year of such an operation. One of the most striking features in the after-history of patients from whom malignant ovaries had been removed was the rapidity with which the cancer recurred in the pelvis, even in cases where the uterus and pelvic peritoneum seemed free from infection at the time of the operation. When surgeons removed bilateral ovarian tumours which appeared to be malignant, they should carefully examine the gastro-intestinal tract, the gall-bladder, and the Fallopian tubes for evidence of primary cancer. If the disease was in a situation favourable for excision it should be removed; and if there was no obvious evidence of dissemination beyond the pelvic organs, it was a useful proceeding to remove the uterus as well as the ovaries. When the primary disease was too advanced for removal the patient's condition was of ten made more bearable, if not comfortable, by the removal of the ovarian masses, but it must be borne in mind that in attempting to do that the lives of patients were often shortened. Finally, a prolonged study of the question strengthened the conviction he formed many years ago, that primary carcinoma of the ovary remained unproven.

Dr. Bernard H. SPILsbury read a paper on the Pathology of Certain Ovarian Tumours, and in the course of his remarks said that he bad encountered malignant metastatic ovarian growths only in very bad cases in which the peritoneal cavity had been flooded with cells. Dr. F. J. MCCANN said that in the light of recent researches it was the duty of surgeons to examine carefully for a primary cancer in these cases, but it was to be remembered that some of these patients were in a desperate condition. Mr. J. D. MALCOLM said that so far as solid tumours were concerned he was inclined to agree with Mr. Bland-Sutton.

\section{OPHTHALMOLOGICAL SOCIETY.}

Marginal Keratectasıa.-Coiloid Exarescences of the Membrane of Bruch.-Endothelioma of the Orbit. - Exhibition of Cases.

A meeting of this society was held on Oct. 20th, Dr. G. A. BERRY, the President, being in the chair.

Mr. Georat CoATs described the pathological features of a case of Marginal Keratectasia formerly shown to the society by $\mathrm{Mr}$. J. H. Fisher. They consisted essentially in a loss of the superficial lamellæ in the periphery of the cornea, and their replacement by a loose vascular fibrous tissue. The membrane of Descemet had undergone enormous compensatory thickening and showed many ruptures plastered over with new layers of hyalin substance. In one area the epithelium was odematous and desquamating, either as a result of commencing ulceration or of leakage from the an terior chamber. From a study of recorded cases it was shown that marginal keratectasia is usually the result of "furrow keratitis" (Schmidt Rimpler) or "marginal atrophy of the cornea" (Fuchs), a condition in which, without ulceration, a groove develops in the upper periphery of the cornea, usually between an arcus and the limbus; ectasia, distortion of the cornea, and astigmatism, against the rule, were produced by the giving way of the floor of the groove. As to pathogenesis there were two opinions: (1) that the condition was purely degenerative; and (2) that it was 